\title{
ANALYSIS OF OXIDATIVE STRESS MARKERS IN CHRONIC CONSUMPTION OF MONOSODIUM GLUTAMATE ON LIVER OF WISTAR ALBINO RATS
}

\author{
SURENDRA BABU THANGACHI*, VARSHA SRIRAM MOKHASI, AGA AMMAR MURTHUZA \\ Department of Anatomy, Vydehi Institute of Medical Sciences and Research Centre, Bengaluru, Karnataka, India. \\ Email: surendra.07here@gmail.com
}

Received: 10 September 2021, Revised and Accepted: 20 October 2021

\section{ABSTRACT}

Objective: The study was intended to explore whether Monosodium glutamate (MSG) induces oxidative stress on the liver of Wistar albino rats when fed chronically at three different doses, namely, low, mid, and high doses identical to human consumption doses in growing countries.

Methods: The acclimatized Wistar albino rats $(n=24)$ were randomly selected and grouped into four groups, namely Control, Low dose MSG (180 mg/kg), Mid dose MSG (360 mg/kg), and High dose MSG (720 mg/kg). The animals were orally administered MSG for 120 days. After completion of the experimental period (120 days), euthanized animal liver was homogenized to investigate the oxidative stress marker enzymes such as Superoxide Dismutase (SOD), Glutathione Peroxidase (GPx), Catalase (CAT), and Myeloperoxidase (MPO).

Results: The MPO showed a significant increase $(\mathrm{p}<0.05)$ in liver homogenate of all MSG induced groups when compared to control group. The SOD, CAT, and GPx activity deteriorated $(\mathrm{p}<0.05)$ in monosodium induced groups contrasting to the control group.

Conclusion: The effects of MSG on oxidative stress markers on liver homogenate in the current study exhibited erratic abnormal changes in oxidative stress markers of monosodium induced groups which contemplate the harmful effects of MSG consumed chronically. The further studies should confirm the genetic basis of oxidative stress damage and transform the safety regulations of MSG consumption throughout the world.

Keywords: Monosodium glutamate, Antioxidant, Oxidative stress, Reactive oxygen species.

(C) 2021 The Authors. Published by Innovare Academic Sciences Pvt Ltd. This is an open access article under the CC BY license (http://creativecommons.org/ licenses/by/4.0/) DOI: http://dx.doi.org/10.22159/ajpcr.2021v14i11.43103. Journal homepage: https://innovareacademics.in/journals/index.php/ajpcr

\section{INTRODUCTION}

The term "food additive" is inevitable in present day lifestyle as global food industry grown exponentially with the use of food flavors to attract consumers globally. In Japan, initial production patent of Monosodium glutamate (MSG) was obtained in 1908 by Professor Kikunae Ikeda [1]. MSG $\left(\mathrm{C}_{5} \mathrm{H}_{8} \mathrm{NO}_{4} \mathrm{Na}\right)$ appears as a white crystalline chemical which is the sodium salt of L-glutamic acid popularly known as Ajinomoto [2]. Most of the packaged foods such as chips, Jelly, Pastry, Candy, Biscuit, Chocolate, French-fries, Pizza, and Noodles contain MSG, which imparts "Umami" or "Savory" or "Broth-like" or "Meaty taste" [3]. The regular daily consumption of MSG in industrialized country is about $0.3-1 \mathrm{~g} / \mathrm{day}$, which is alarmingly increasing many times in developing countries [4]. The increased consumption of MSG around the globe is proportional to its increased production, especially major share of production by countries of Asia [5]. The controversies regarding the safety of MSG dietary consumption still sparks the debate among scientists even though FDA announced "MSG as safe for human consumption" [6]. The free radicals constitute highly reactive, unpaired electrons produced during cellular metabolism, which tries to form pairs with other electrons and one such group of free radicals are Reactive Oxygen Species (ROS) [7]. ROS is composed of superoxide, hydrogen peroxide, hydroxyl radicals, and singlet oxygen. The oxidative stress is the imbalance between ROS and body's antioxidant defense system which causes lipid peroxidation, oxidative DNA damage, disrupts signal transduction in living cell [8]. The liver is a vital accessory gastrointestinal organ which plays a pivotal role in carbohydrate, protein and fat metabolism. The liver not only detoxifies waste products, but also secretes bile, synthesize lipoprotein, produces plasma proteins including clotting factors, and many more functions. The high metabolic activity of the liver attributes to its increase in free radical production naturally, which is counteracted by the endogenous antioxidant system [9]. Oxidative stress in the liver induced by MSG can be explained by exhausting endogenous antioxidants namely Catalase (CAT), Superoxide dismutase (SOD), and reduced glutathione $[10,11]$. Most of the animal studies concerned with MSG fail to clarify the comparative human dosage along with the route of administration [12]. Therefore, we tried to explore whether chronic consumption of MSG at three different doses (low, mid, and high) induces oxidative stress in liver of Wistar albino rats based on human consumption of MSG.

\section{METHODS}

Animals

The study was conducted with twenty four adult Wistar albino rats of either sex $(n=24)$. The approval for the study was granted by the Institutional Animal Ethical Committee (IAEC) with reg no: VIMS/ IAEC/2016/03. The Institutional animal house facility was well maintained with $23 \pm 1^{\circ} \mathrm{C}$ and $12 \mathrm{~h}$ light $/ 12 \mathrm{~h}$ dark cycle. The rats were provided with surplus standard laboratory chow and drinkable water. The animals recruited for the study were acclimatized before the inception of the study. Committee for the Purpose of Control and Supervision of Experiments on Animals guidelines were pursued for animal handling as well as procedural protocols for the experiment.

\section{Experimental design}

The acclimatized animals for the study were randomly chosen and grouped ( $\mathrm{n}=6$ per group) for the experimentation conducted for a chronic period of 120 days. The Wistar albino rats were organized into four groups ( $\mathrm{n}=6$ per group) as follows:

a. Group I (Control) - The rats were fed with distilled water

b. Group II (Low dose) - The rats were given MSG of $180 \mathrm{mg} / \mathrm{kg}$ body wt

c. Group III (Mid dose) - The rats were given MSG of $360 \mathrm{mg} / \mathrm{kg}$ body wt

d. Group IV (High dose) - The rats were given MSG of $720 \mathrm{mg} / \mathrm{kg}$ body wt. 
The food grade MSG was administered to the experimental rat's daily using oral gavage for a chronic period (120 days) as per the design of the study.

\section{Oxidative stress markers assessment}

After the end of the chronic experiment period, animals were euthanized using cervical dislocation and abdomen of animal was dissected out to harvest liver. One part of the liver sample from each animal was homogenized, centrifuged at $12000 \mathrm{RPM}\left(2^{\circ} \mathrm{C}\right)$ for $10 \mathrm{~min}$ and the supernatant was collected for oxidative stress marker analysis. The enzymes for oxidative stress, namely SOD, Glutathione Peroxidase (GPx), CAT, and Myeloperoxidase (MPO) were estimated using Enzyme Linked Immunosorbent Assay (ELISA) plate method. The doubleantibody sandwich ELISA technique was employed for the oxidative stress marker assay to get higher specificity and increased sensitivity.

\section{Statistical analysis}

The statistically analyzed data were expressed as mean \pm standard deviation (SD). GraphPad Prism software 9.1.2 was adopted for data analysis statistically. The data were subjected to One-way ANOVA analysis and followed by Tukey's post hoc test. After analysis, the results were considered significant if $p<0.05$. The $p$-values in the present experiment were illustrated as $*$ for $\mathrm{p}<0.05,{ }^{* *}$ for $\mathrm{p}<0.01$, ${ }^{* * *}$ for $\mathrm{p}<0.001,{ }^{* * * *}$ for $\mathrm{p}<0.0001$.

\section{RESULTS}

The study results found significant differences $(p<0.05)$ in oxidative stress markers between control and MSG induced groups. Administration of MSG significantly $(\mathrm{p}<0.05)$ escalated MPO in MSG induced groups when compared with control group (Fig. 1). MPO activity drastically increased up to $77.30 \%$ in high dose MSG while low and mid dose MSG induced groups showed $24.11 \%$ and $35.94 \%$, respectively. The activities of SOD in MSG induced groups significantly $(\mathrm{p}<0.05)$ decreased contrasting to control group (Fig. 2). The present recording of SOD activity showed $21.41 \%, 29.12 \%$, and $41.23 \%$ decreased in low, mid, and high dose MSG groups compared to control group. The CAT activity significantly $(\mathrm{p}<0.05)$ decreased in MSG induced group when analyzed with control group (Fig. 3). The determined $13.48 \%, 23.67 \%$, and $29.79 \%$ reduction in CAT for low, mid, and high dose MSG groups, respectively, were noted during the analysis. The GPx showed $14.91 \%, 22.76 \%$, and $30.35 \%$ reduced in low, mid, and high dose MSG induced groups compared to control group significantly $(\mathrm{p}<0.05)$ (Fig. 4).

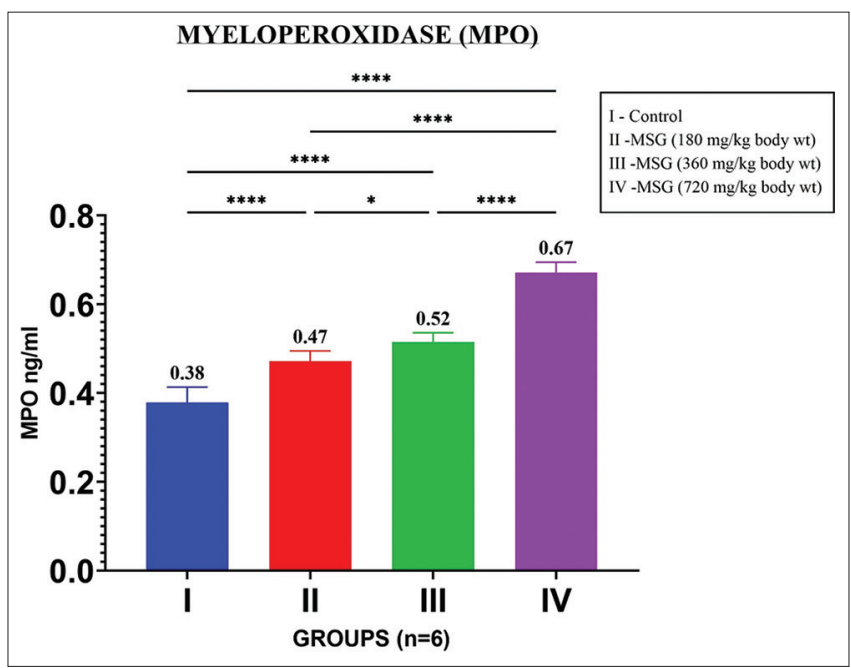

Fig. 1: Effect of Monosodium glutamate on Myeloperoxidase in liver homogenate. (Values are expressed as mean \pm SD. $*$ Significantly different from the control group at $\mathbf{p}<0.05$.

**Significantly different from the control group at $\mathbf{p}<0.01$.

$* * *$ Significantly different from the control group at $\mathbf{p}<0.001$.

****Significantly different from the control group at $\mathbf{p}<0.0001$ )

\section{DISCUSSION}

The present study investigated the effects of MSG at different doses inducing oxidative stress in the rat liver tissue with the spotlight on the human corresponding dosage of MSG at low, mid, and high dosage chronically viewing the consumption in developing Asian countries. The previous research findings did show oxidative stress changes in various organ systems of animal model but failed to corroborate definitive conclusions as those study design had MSG doses varied from human consumption and differed in route of administration [12].

The current study investigations expressed that there were abnormal variations in oxidative stress markers of liver tissue after administration of MSG chronically. The significant abnormal increase was recorded in MPO activity in high dose MSG group and marked increase in low and mid dose groups. The MPO is the crucial oxidative stress marker and marker

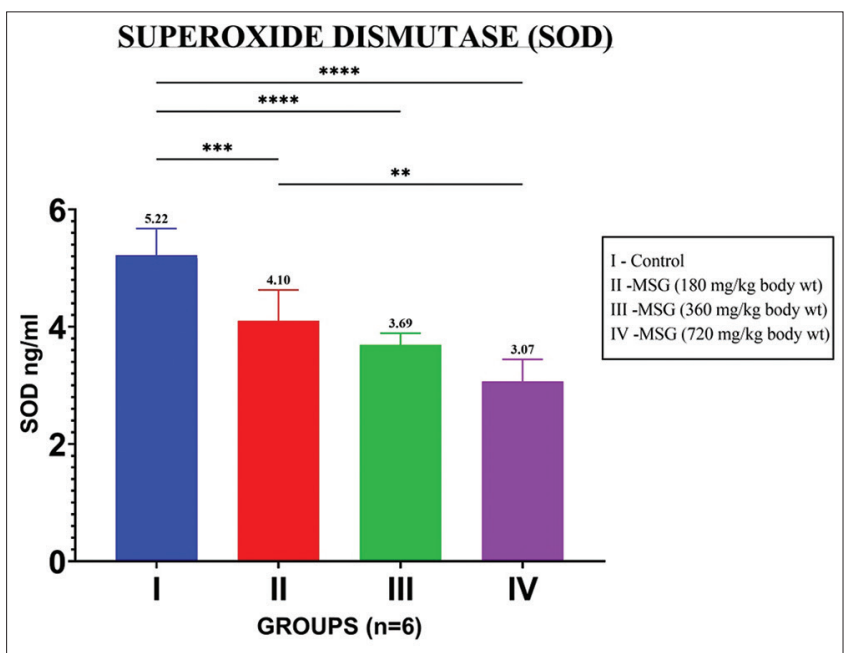

Fig. 2: Effect of Monosodium glutamate on Superoxide Dismutase in liver homogenate. (Values are expressed as mean \pm SD. *Significantly different from the control group at $\mathbf{p}<0.05$. **Significantly different from the control group at $p<0.01$.*** Significantly different from the control group at $\mathbf{p}<0.001$. $* * * *$ Significantly different from the control group at $\mathbf{p}<0.0001$ )

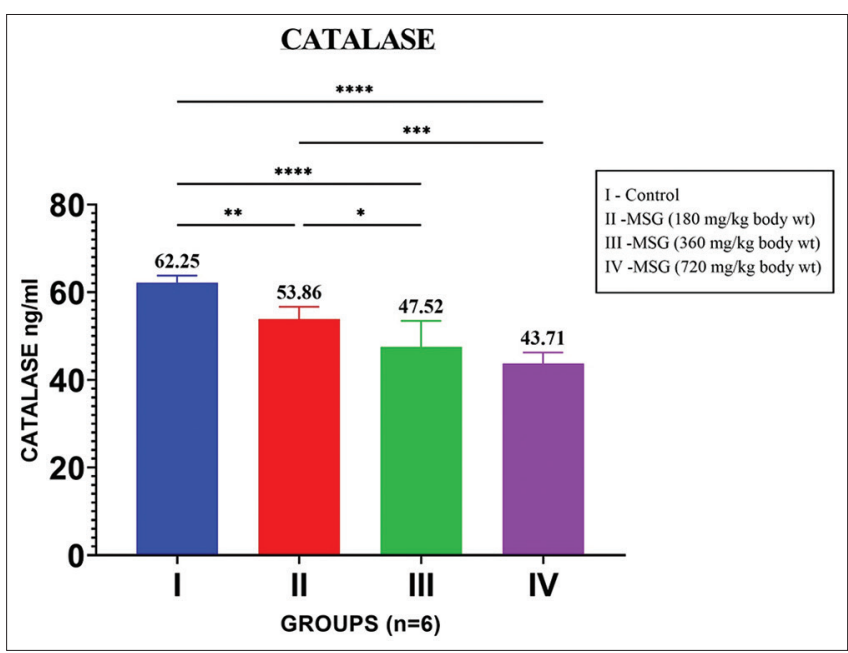

Fig. 3: Effect of Monosodium glutamate on Catalase in liver homogenate. (Values are expressed as mean \pm SD. *Significantly different from the control group at $p<0.05$. ${ }^{*}$ Significantly different from the control group at $\mathbf{p}<0.01$. ${ }^{* * *}$ Significantly different from the control group at $\mathbf{p}<0.001$. ${ }^{* * * *}$ Significantly different from the control group at $p<0.0001$ ) 


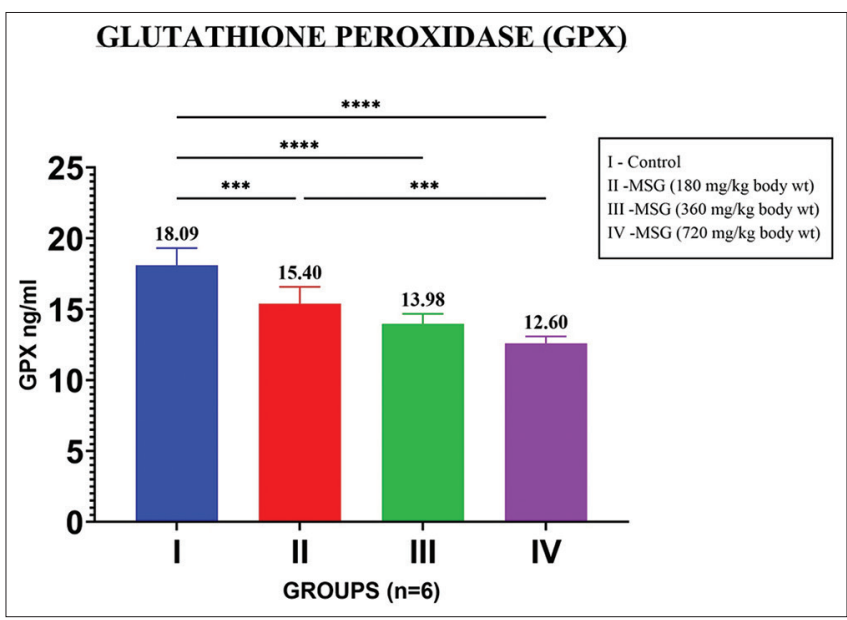

Fig. 4: Effect of Monosodium glutamate on Glutathione Peroxidase in liver homogenate. (Values are expressed as mean \pm SD. *Significantly different from the control group at $\mathbf{p}<0.05$. **Significantly different from the control group at $\mathbf{p}<0.01$. ***Significantly different from the control group at $\mathbf{p}<0.001$. $* * * *$ Significantly different from the control group at $\mathbf{p}<0.0001$ )

for inflammation [13]. The MSG has adversely affected liver tissue by inducing oxidative stress at all doses in our current study. The present investigation findings show that SOD levels were significantly declined in all MSG induced group as a result of MSG administration [11,14]. The declined SOD levels may indicate an increase in ROS such as superoxide radical and hydrogen peroxide which further speculate that these ROS may damage the DNA and lipid bound biological membrane in liver cells [15]. The CAT activity in cellular redox status is crucial for converting hydrogen peroxide into water. The CAT in the current study decreased substantially in monosodium induced groups which may be suggestive of definitive imbalance in the redox status of liver cell [16]. The altered SOD and CAT levels in liver tissue may be detrimental in the oxidative stress pathophysiology by disrupting signal transduction, cellular mechanisms in the cell leading to apoptotic changes in liver $[17,18]$. The GPX endogenously scavenges hydrogen peroxide in liver tissue and declined levels of GPX in MSG induced groups in the present study may indicate an alarming increase of ROS damaging the hepatic cellular inclusions [19]. The redox status imbalance would have either decreased vital endogenous antioxidant enzymes by increasing ROS in MSG administered groups $[5,20]$.The results can also be corroborated to glycation of the endogenous antioxidant enzymes by MSG may also make these antioxidant enzymes inactive [21]. The DNA damage in liver cells may be attributed to the modifications in purines and pyrimidine, DNA repair enzymes, and DNA polymerases leading to mutation in DNA. The oxidative stress is leading cause of several hepatic diseases that has to be addressed clinically to improve the overall hepatic tissue health $[17,22]$. The increase in ROS and oxidative stress can also trigger the apoptosis in the cells $[23,24]$. The present study may speculate that oxidative stress induced by MSG after chronic administration may lead to a variety of hepatic diseases such as Non-Alcoholic Fatty Liver Disease, Non-Alcoholic Steatohepatitis if not addressed with healthy food supplements containing exogenous antioxidants.

\section{CONCLUSION}

The present study findings show that MSG induces oxidative stress in the liver of Wistar albino rats on chronic consumption. The safety concern of MSG must be reconsidered by the food industry and government agencies to culminate the progression of liver diseases by its chronic usage. The healthy lifestyle changes involving physical exercises and regular consumption of foods rich with antioxidants may reduce the oxidative stress. The future perspective of MSG research should focus on various genetic and epigenetic changes induced by MSG at the molecular level in liver tissue to understand clear pathogenesis of MSG.

\section{ACKNOWLEDGMENTS}

The authors acknowledge the constant support of Vydehi Institute of Medical Sciences and Research Centre, Bengaluru, India for accomplishing the research work.

\section{AUTHORS' CONTRIBUTION}

Surendra babu Thangachi formulated the present study, executed data collection, data analysis, and penned the manuscript. Varsha Sriram Mokhasi was instrumental in guiding throughout the study and edited the manuscript. Aga Ammar Murthuza was constructive in helping for manuscript writing

\section{CONFLICTS OF INTEREST}

The authors announce that there were no conflicts of interest in current research work.

\section{FINANCIAL SUPPORT}

None.

\section{REFERENCES}

1. Sano C. History of glutamate production. Am J Clin Nutr 2009;90:728-32

2. Win DT. MSG-flavor enhancer or deadly killer. AU J Technol 2008; $12: 43-9$

3. Sharma V, Deshmukk RA. A fifth taste or bio bomb. Eur J Pharma Med Res 2015;2:381-400.

4. Henry-Unaeze HN. Update on food safety of monosodium l-glutamate (MSG). Pathophysiology 2017;24:243-9.

5. Kazmi Z, Fatima I, Perveen S, Malik SS. Monosodium glutamate: Review on clinical reports. Int J Food Prop 2017;20:1-9.

6. Datta A, Hossain A, Roy S. An overview on monosodium glutamate: Its direct and indirect effects. Res J Pharm Technol 2019;12:6187-92.

7. Sies H. What is oxidative stress? In: Developments in Cardiovascular Medicine. Boston, MA: Springer; 2000. p. 1-8

8. Yoshikawa T, Naito Y. What is oxidative stress? Jap Med Assoc J 2002;45:271-6.

9. Arauz J, Ramos-Tovar E, Muriel P. Redox state and methods to evaluate oxidative stress in liver damage: From bench to bedside. Ann Hepatol 2016;15:160-73

10. Farombi EO, Onyema OO. Monosodium glutamate-induced oxidative damage and genotoxicity in the rat: Modulatory role of Vitamin C, Vitamin E and quercetin. Hum Exp Toxicol 2006;25:251-9.

11. Eid RA, Al-Shraim M, Zaki MS, Kamar SS, Abdel Latif NS, Negm S, et al. Vitamin E protects against monosodium glutamate-induced acute liver injury and hepatocyte ultrastructural alterations in rats. Ultrastruct Pathol 2019;43:199-208.

12. Zanfirescu A, Ungurianu A, Tsatsakis AM, Nițulescu GM, Kouretas D, Veskoukis A, et al. A review of the alleged health hazards of monosodium glutamate. Compr Rev Food Sci Food Saf 2019;18:1111-34.

13. Lestarisa T, Alexandra FD, Jelita H, Suhartono E. Myeloperoxidase as an indicator of liver cells inflammation induced by mercury. Int J Pharm Clin Res 2016;15:1516-21.

14. Del Carmen Contini M, Millen N, Riera L, Mahieu S. Kidney and liver functions and stress oxidative markers of monosodium glutamateinduced obese rats. Food Public Health 2012;2:168-77.

15. Zhu R, Wang Y, Zhang L, Guo Q. Oxidative stress and liver disease: Oxidative stress and liver disease. Hepatol Res 2012;42:741-9.

16. Albrahim T, Binobead MA. Roles of Moringa oleifera leaf extract in improving the impact of high dietary intake of monosodium glutamate-induced liver toxicity, oxidative stress, genotoxicity, DNA damage, and PCNA alterations in male rats. Oxid Med Cell Longev 2018;2018:4501097.

17. Li S, Tan HY, Wang N, Zhang ZJ, Lao L, Wong CW, et al. The role of oxidative stress and antioxidants in liver diseases. Int J Mol Sci 2015;16:26087-124.

18. Naito Y, Lee MC, Kato Y, Nagai R, Yonei Y. Oxidative stress markers. Anti Aging Med 2010;7:36-44.

19. Hareeri NA, Alrasheedi AA, Eassaw MM. Effect of sesame on liver enzymes and lipid profile inrats exposed to oxidative stress induced by monosodium glutamate. J Am Sci 2017;13:71-8.

20. Chakraborty SP. Patho-physiological and toxicological aspects of 
monosodium glutamate. Toxicol Mech Methods 2019;29:389-96.

21. Okwudiri O. Monosodium glutamate induces oxidative stress and affects glucose metabolism in the kidney of rats. Int J Biochem Res Rev 2012;2:1-11.

22. Cichoż-Lach H, Michalak A. Oxidative stress as a crucial factor in liver diseases. World J Gastroenterol 2014;20:8082-91.

23. Pavlovic V, Pavlovic D, Kocic G, Sokolovic D, Jevtovic-Stoimenov T,
Cekic S, et al. Effect of monosodium glutamate on oxidative stress and apoptosis in rat thymus. Mol Cell Biochem 2007;303:161-6.

24. Quines CB, Chagas PM, Hartmann D, Carvalho NR, Soares FA, Nogueira CW. (p-ClPhSe)2 reduces hepatotoxicity induced by monosodium glutamate by improving mitochondrial function in rats: $(\mathrm{P}-\mathrm{ClPhSe}) 2$ reduces hepatotoxicity induced by MSG. J Cell Biochem 2017;118:2877-86. 